\title{
Projetos de Letramento no Ensino Médio: novas perspectivas e desafios
}

\begin{abstract}
Karoliny Correia'
'Universidade Federal de Santa Catarina (UFSC), Florianópolis/SC - Brasil

RESUMO - Projetos de Letramento no Ensino Médio: novas perspectivas e desafios. Este artigo discute as implicações das novas perspectivas do ensino e aprendizagem de língua materna, em especial o trabalho centrado em projetos que tomam a prática social e as demandas dos sujeitos como ponto de partida para as ações metodológicas, e se volta para a análise de um projeto de letramento realizado no Programa Institucional de Bolsa de Iniciação à Docência (PIBID) do curso de Letras Português da UFSC, que se deu por meio de uma pesquisa-ação (Thiollent, 2008) em uma turma de terceiro ano do Ensino Médio de uma escola pública. As conclusões levam a crer que a falta de engajamento dos alunos pode ter se dado em função da distinção entre práticas de letramento escolares e familiares, demandando ressignificações metodológicas na formulação de projetos de letramento.

Palavras-chave: Língua Materna. Práticas de Letramento. Projetos de Letramento.
\end{abstract}

ABSTRACT - Literacy Projects in Secondary Education: new perspectives and challenges. This paper discusses the impact of new perspectives of native language teaching and learning. In this sense, it is focused on projects that take not only the social practice but also the student's demands as the starting point for methodological actions. It addresses a literacy project carried out in the Institutional Scholarship for Teaching Initiation Program (PIBID) at the Undergraduate Portuguese Course from UFSC. The mentioned project was developed through a research-action (Thiollent, 2008) in a secondary education third year class of a public school. The results suggest that the students' lack of engagement may have been due to the distinction between school and family literacy practices, requiring a methodological redefinition in the formulation of new literacy projects.

Keywords: Native Language. Literacy Practices. Literacy Projects.

Educação \& Realidade, Porto Alegre, v. 41, n. 1, p. 259-277, jan./mar. 2016. http://dx.doi.org/10.1590/2175-623653625 


\section{Introdução}

A partir da década de 1990, por motivação da Nova Crítica ao Ensino de Português (Britto, 1997) e dos estudos do campo linguístico, o contexto educacional brasileiro, especialmente o ensino de língua materna, voltou-se para um movimento de reformulação das práticas de ensino e aprendizagem até então vigentes. As novas teorizações, advindas do campo das ciências da linguagem, passaram a nortear a produção de documentos oficias de ensino, como os Parâmetros Curriculares Nacionais (Brasil, 1998), que objetivavam servir de referência para as discussões curriculares. Conceitos como gêneros discursivos (Bakhtin, 2003) e letramentos (Street, 1984; 1988; 2003) ganharam força nas discussões de ressignificação do novo cenário educacional brasileiro, sobretudo no contexto de formação docente.

Nesse cenário, os Novos Estudos do Letramento ${ }^{1}$, impulsionados pela ancoragem na antropologia e na sociologia, e em especial no método etnográfico ${ }^{2}$, contribuíram para o estudo das práticas de uso social da escrita, com conceitos como eventos de letramentos (Heath, 2001) e práticas de letramento (Street, 1988). Ancorada nesses estudos e visando a ressignificação das práticas de ensino e aprendizagem, Kleiman (2005) empreende uma discussão sobre a necessidade de o professor ser um agente de letramento e ancorar suas metodologias em projetos de letramento, implicando uma nova postura do professor em sala de aula, de forma a imergir os alunos em práticas significativas.

As práticas escritas estão presentes na maioria das esferas sociais, em maior ou menor complexidade, sendo utilizadas das mais diversas formas. Desse processo decorre a importância de estudos que permitam entender a diversidade e a riqueza dos usos sociais da escrita nos diferentes agrupamentos humanos. Consciente dessas questões, buscou-se por meio deste estudo compreender as implicações das novas perspectivas do ensino e aprendizagem de língua materna, em especial o trabalho centrado nos projetos de letramento. O estudo se volta para a análise de um projeto de letramento realizado no Programa Institucional de Bolsa de Iniciação à Docência (PIBID) do curso de Letras Português da UFSC, que se a partir de uma pesquisa-ação (Thiollent, 2008) em uma turma de terceiro ano do Ensino Médio de uma escola pública, e visa articular as características desse trabalho metodológico, os desafios e os resultados obtidos nesse processo.

Para ancorar a análise, foram agenciadas teorizações sobre o letramento com base em Street (1984; 1988; 2003), Heath (2001), Barton e Hamilton (2004), Barton, Hamilton e Ivanic (2000) e de estudos de Kleiman (1995; 1998; 2005; 2006; 2007; 2009), entre outros autores que discutem os novos estudos de letramento por meio de perspectivas etnográficas e que contribuem para a ampliação do quadro teórico-epistemológico do campo da Linguística Aplicada. 


\section{Letramentos: teorizações significativas para o contexto educacional}

A crescente demanda e a importância do uso da escrita no mundo contemporâneo suscitaram o empreendimento de discussões em torno dos papéis dessa modalidade da língua nas práticas sociais pelos Novos Estudos do Letramento. Tais estudos, de base essencialmente etnográfica e antropológica, foram divulgados no Brasil por Angela Kleiman, Magda Soares, entre outros nomes no cenário nacional, tendo como suporte as concepções teóricas de autores como Brian Street, Shirley Heath, e Harvey Graff, direcionando novos olhares à expansão de teorizações em relação à modalidade escrita da língua.

Nessa discussão, o letramento, que por muito tempo foi considerado sinônimo de alfabetização, passou a caracterizar-se como "[...] um conjunto de práticas sociais que usam a escrita enquanto sistema simbólico e enquanto tecnologia, em contextos específicos, para objetivos específicos" (Kleiman, 1995, p. 19), distinguindo-se assim de um mero processo instrumental do domínio da língua (Soares, 1998). Para Rojo (2009), o letramento implica empoderamento, ou seja, a possibilidade de o sujeito atuar nas mais distintas esferas da atividade humana, o que acaba incidindo no processo de construção identitária. Por esse viés, pode-se considerar que as teorizações sobre alfabetização de Freire (2006) se vinculam muito mais à concepção de letramento atual do que propriamente de alfabetização em seu sentido mais estrito, pois o autor vê a alfabetização de forma mais ampla, por meio de uma perspectiva crítica, não restrita ao processo de aquisição do código.

Nesse contexto, segundo Barton e Hamilton (2004), os conceitos de práticas e eventos de letramento, oriundos dos novos estudos do letramento, têm mostrado uma contribuição significativa para a compreensão das práticas sociais que fazem o uso da modalidade escrita, uma vez que a escrita e seus usos sociais permeiam a maior parte das atividades de interação humana. O conceito de eventos de letramento, proposto por Heath (2001), por exemplo, designa as situações em que um texto escrito esteja presente e sendo utilizado para construção de sentidos na interação com o outro, sendo considerados, dessa forma, eventos visíveis. Por sua vez, o conceito de práticas de letramento, proposto por Street (1988), é visto como algo mais amplo, que dá sustentação aos eventos de letramento, implicando o conjunto de vivências, de valores e experiências que envolvem a modalidade escrita da língua. Apesar de não serem visíveis - remissão à metáfora do iceberg de Hamilton (2000) - as práticas podem ser depreensíveis a partir dos eventos. É dessa forma que, para Barton e Hamilton (2004), os eventos são excelentes pontos de partida para a investigação no campo do letramento, pois a partir da identificação dos eventos podemos depreender as práticas envolvidas nesse processo. 
Projetos de Letramento no Ensino Médio

Além de todas essas considerações, os estudos do letramento, assim como os conceitos de práticas e eventos de letramento, impulsionam o desenvolvimento de novas práticas de ensino e aprendizagem, bem como o processo de desmistificação de práticas anteriores. Por meio desses estudos, podem-se ampliar as compreensões do que se entende por usos sociais da escrita, favorecendo a implementação de novos projetos, especialmente de cunho etnográfico, e de programas capazes de dar conta dos problemas linguísticos socialmente relevantes (Moita-Lopes, 2006). Assim como ressalta Kalman (2003), é importante compreender as diversas formas de participação, construção do acesso e os processos de apropriação da leitura e da escrita, mesmo no que se refere aos usos cotidianos da língua, para desenvolvermos formas enriquecedoras de ensino da leitura e da escrita e elaborar novas formas de interagir com os alunos, a fim de promover atividades significativas para suas vidas.

É válido ressaltar, no entanto, que, assim como para Kleiman (2005), o letramento envolve uma ação coletiva e se constitui como uma prática situada (Barton; Hamilton; Ivanic, 2000) e sensível, mas que não se limita às práticas de uso da língua na esfera escolar, pois torna visível a multiplicidade do papel da escrita na vida social fazendo com que o aluno possa "[...] adquirir o conhecimento necessário para agir em uma situação específica” (Kleiman, 2005, p. 10). A desatenção a esses fatores, segundo Kleiman (2005), estimula a desconsideração das particularidades dos alunos, pautada no modelo autônomo adotado pela escola, mas que poderia ser revertida a partir da focalização de atividades contextualizadas na prática social. Isso implica dizer que apesar de a escola ser considerada uma das mais importantes agências de letramento (Kleiman, 1995), não é somente no contexto escolar que se constrói o acesso à cultura escrita e a possibilidade de sua apropriação (Kalman, 2003), mas sim na interação com o outro.

\section{Práticas de Ensino e Aprendizagem: do modelo autônomo ao modelo ideológico de letramento}

A partir dos novos estudos do letramento, passou-se a discutir as implicações de um ensino exclusivamente voltado ao modelo autônomo de letramento (Street, 1984; 2003), que, em boa medida, tem desconsiderado as particularidades dos sujeitos envolvidos no processo escolar e imposto, sem um estudo acurado das necessidades e práticas de letramento dos alunos, o letramento dominante.

O modelo autônomo de letramento, comumente adotado pela esfera escolar, caracteriza-se por apresentar práticas de ensino centradas nas relações hegemônicas, o que, de certa maneira, implica a desconsideração do contexto e das particularidades das vivências dos alunos (especialmente as diferentes formas com que lidam com a escrita) mediante a imposição de conteúdos universais e neutros. Nesse caso, os 
sujeitos letrados são necessariamente alfabetizados e essa condição lhes confere progresso e maior mobilidade social, promovendo, assim, um processo de estigmatização em relação àqueles que não dominam a modalidade escrita da língua. Nessa concepção acredita-se que, conforme sinaliza Street (2003, p. 4), “[...] em si mesmo o letramento - de forma autônoma - terá efeitos sobre outras práticas sociais e cognitivas", ou seja, que o domínio da escrita reflete diretamente no desenvolvimento do pensamento abstrato, considerando, assim, que quem não domina a escrita não tem a capacidade de abstração nem mesmo raciocínio lógico, e consequentemente no progresso social, ignorando-se, por sua vez, as formas pelas quais esses sujeitos se movem nas esferas sociais. Trata-se de um conjunto de concepções focadas nas habilidades individuais dos sujeitos, tomados independentemente dos contextos sociocultural e histórico em que se inserem. Nesse modelo, segundo Kleiman (1995), a escola preocupa-se mais com um tipo de letramento - a alfabetização - do que com a prática social.

A reversão desse quadro requer que as atividades de ensino e aprendizagem se ancorem em uma perspectiva ideológica de letramento, ou seja, no modelo ideológico (Street, 1984), que sugere uma atitude sensível culturalmente frente às práticas pedagógicas, o que implica, entre outras questões, uma abordagem etnográfica que focalize a língua de forma situada e em seus usos sociais, com o intuito de serem transformadoras da vida social (Street, 2003). Tal atitude se justifica porque há múltiplas práticas de letramentos e cada grupo apresenta um significado particular para a escrita. Apesar dessa postura sensível, o modelo ideológico, segundo Kleiman (1995), abrange mais do que aspectos culturais, mas também questões de poder e ideologia, pois as práticas escolares são ideologicamente determinadas, o que implica a consideração de apenas uma das práticas de letramento, geralmente a das classes sociais detentoras do poder, determinando, assim, a superioridade do letramento dominante na escola. Quanto a essa discussão, Street (2003, p. 4) esclarece que

\begin{abstract}
Esse modelo parte de premissas diferentes das adotadas pelo modelo autônomo - propondo por outro lado que o letramento é uma prática de cunho social, e não meramente uma habilidade técnica e neutra, e que aparece sempre envolto em princípios epistemológicos socialmente construídos. [...] as versões específicas sobre ele serão sempre ideológicas, serão sempre fundamentadas em uma visão particular do mundo, e com frequência em um desejo de que aquela visão do letramento seja dominante e que venha a marginalizar outras.
\end{abstract}

Segundo Street (2003), apesar das críticas em torno da supremacia do letramento dominante (global), o letramento ideológico não sugere uma romantização dos letramentos vernaculares (locais), mas sim um processo de hibridização dos letramentos locais e globais. O que se 
observa no contexto educacional, contudo, é uma tímida consideração dos letramentos vernaculares, que, nos últimos anos, tem sido posta em discussão. Segundo Kalantzis e Cope (2006), o processo de hibridização sugerido e estimulado pelos novos estudos do letramento tem encontrado barreiras, pois, em geral, a escola acolhe alunos provenientes de estratos sociais distintos, tendendo a que a recepção desse processo seja diferente de aluno a aluno, dependendo de sua maior ou menor familiaridade/convergência com as representações de mundo contempladas na escola. Esse contexto deveria resultar, portanto, na consideração das práticas dos alunos sem a imposição de modelos padronizados e descontextualizados, pois se assim não fosse haveria fracassos nos projetos de letramento, motivados pelo desinteresse e pela falta de sentido dessas práticas e eventos de letramentos dominantes. Para Freire (2006, p. 13), as práticas de ensino e aprendizagem "Deveriam vir carregadas da significação de sua experiência existencial [do aluno] e não da experiência do educador".

Em meio às contribuições do modelo ideológico de letramento, é relevante, assim como nos alerta Gee (1994), que não nos enganemos ao pensar que o acesso ao letramento dominante automaticamente garantirá igualdade e mobilidade social, pois as práticas discursivas sempre se baseiam na perspectiva de algum grupo social. Por essa razão, segundo Freire (2006), a atividade educativa é um processo político e tem forte vínculo com as questões de poder e, portanto, deve instigar no aluno uma atitude crítica em relação ao senso comum e à hegemonia que impera na sociedade, e ao mesmo tempo “[...] uma visão de mundo que, dado seu poder aqui e mundo afora, deve ser vista criticamente, comparativamente e com constante senso de possibilidades de mudança" (Gee, 1994, p. 68). Nesse sentido, deve-se combater a posição ideológica (Freire, 2006) de que só se estuda na escola e dar ao aluno o direito a conhecer melhor o que já conhece e de conhecer o que ainda não conhece.

Para Kalantzis e Cope (2006), assim como para Freire (2006), a educação faculta uma maior mobilidade aos sujeitos, especialmente em relação à participação política, eis a necessidade de oferecer aos alunos representações distintas das suas. O processo de hibridização, nesse viés, não significa partir das experiências dos alunos (verticalizar), mas sim considerar as vivências desses sujeitos e não transformá-las, expandindo-as (perspectiva horizontalista), o que repercute na valorização não só do letramento dominante, como também do vernacular. Para esses autores, a escola é um lugar de encontro de representações distintas de mundo, onde circulam grupos diferentes, cabendo a ela pensar em uma perspectiva situada. Além de facultar a mobilidade social do aluno, segundo Kleiman (1998), a escola deveria ressignificar a identidade dele por meio de uma ação reflexiva, sendo necessário compreender as identidades desses estudantes e suas práticas sociais.

Desse processo decorre o caráter dialógico e interlocutivo da educação, ou seja, ao mesmo tempo em que os alunos têm “[...] o direito 
de dizer a sua palavra. Direito deles de falar a que corresponde o nosso dever de escutá-los [...] ao dever de escutá-los corresponde o direito que igualmente temos de falar a eles [...] falar com eles" (Freire, 2006, p. 17, grifo do autor). Isso converge com a perspectiva histórico-cultural e com uma ação pedagógica que envolve a palavra do aluno e a contrapalavra do professor (Britto, 1997), de forma a permitir a intervenção política do sujeito no mundo em que vive. Essa atividade suscita a produção de sentidos no processo interlocutivo, que se dá por meio da negociação e da consideração do conhecimento prévio dos alunos. É o que propõe Geraldi (2003, p. 135) quando afirma que a "[...] inserção das atividades linguísticas de sujeitos historicamente situados e datados [deve ser tomada] como o lugar da ação e como o objeto da ação do ensino de língua materna".

No modelo autônomo de letramento, a assimetria que se dá em sala de aula se transforma em autoridade, desqualificando, desse modo, as contribuições dos alunos. Assim como Duarte (2001), contudo, acreditamos numa assimetria constitutiva da relação entre professor e aluno em sala de aula, que se dá também no modelo ideológico, sem vincular-se, portanto, a uma perspectiva bancária de letramento (Freire, 1975), pois o ato de ensinar é fundamental e não deve ser deixado às margens. Nesse sentido, a polêmica da assimetria na relação professor-aluno não deve ser fundamentada no silenciamento de uma das partes, mas sim na ação do professor em agir na zona de desenvolvimento imediato (ZDI) de quem é menos experiente (Vigotski, 2000) e ressignificar suas representações de mundo por meio do acesso aos saberes por ele desconhecidos. Além disso, diferentemente da perspectiva do ato de ensinar focada no processo de transmissão de saberes, o princípio de que ensinar é fundamental, na perspectiva de Duarte (2001), não se centra na transmissão do conhecimento, mas sim em sua apropriação, numa relação de díade, de troca de experiência.

Por essa razão, o deslocamento de um ensino centrado estritamente no modelo autônomo para um ensino vinculado ao modelo ideológico ${ }^{3}$ sugere ações mais consequentes dos professores, enfatizando a importância de se considerar os saberes dos alunos e suas experiências. Eis a necessidade de promover eventos de letramento que implementem, de fato, os usos da escrita, fazendo ressignificar e ampliar, assim, as práticas de letramento dos alunos.

\section{De Mediador a Agente de Letramento: uma estratégia de reformulação das práticas pedagógicas por meio de projetos de letramento}

Considerando o modelo ideológico de letramento, a ancoragem epistemológica da ação docente passou a ser a da perspectiva de língua como objeto social, o que implicou, dentre outras vertentes, teorizações sobre os gêneros do discurso e sobre o letramento. Nesse contexto, con- 
Projetos de Letramento no Ensino Médio

tudo, é importante que se focalizem dois papéis atribuídos ao professor em sala de aula, o de mediador e o de agente de letramento.

Os papéis e as imagens atribuídas ao professor, segundo Oliveira (2010b), são historicamente construídos de acordo com suas ações em sala de aula e tendem a subsidiar o trabalho docente nas práticas pedagógicas. Nesse contexto, de uma imagem de transmissor dos saberes, pautada numa relação autoritária e monovocal, característica do modelo autônomo de letramento, o professor passou a uma imagem de mediador, vinculada a um processo de apropriação do conhecimento.

A imagem do professor como mediador, contudo, apesar de tentar superar a metáfora do conhecimento transmitido (Oliveira, 2010b), tem sido interpretada de maneira equivocada, tomada como metáfora espacial cotidiana (Kleiman, 2006), pois considera a representação social do professor mediador como aquele que está no meio, como um sujeito que tem papel intermediário e não de construção conjunta de conhecimento. Longe de indicar aquele "[...] que exerce um papel intermediário entre dois interessados numa negociação, naquele que arbitra" (Kleiman, 2006, p. 80), tal conceito se vincula às concepções de Vigotski sobre a consideração da linguagem como instrumento psicológico de mediação simbólica, mais especificamente sobre a importância da interação para o processo de desenvolvimento das funções superiores dos alunos e para a construção do conhecimento.

Surge, assim, a necessidade de o professor agir como um agente de letramento (Kleiman, 2006), ou seja, como mobilizador de conhecimentos prévios, de estratégias e de recursos necessários para a inserção dos alunos em práticas sociais de letramento em contexto escolar, além de facultar-lhes a participação nas práticas sociais de uso situado da escrita. Nesse caso, o professor afasta-se da concepção de reprodutor de conhecimento e da relação hierarquizante em sala de aula, vinculadas ao modelo autônomo de letramento (Street, 1984). Nesse quadro, a concepção de ensino da escrita dos estudos do letramento vê a relação entre professor e aluno como uma atividade de cooperação e, dessa forma, de interação (Kleiman, 2006), reconhecendo a importância do interlocutor mais experiente (Vigotski, 2000) no processo de apropriação do conhecimento. O professor deve ser autônomo, no sentido daquele que toma decisões e está engajado em ações, modificando seu plano de ação quando o contexto e as necessidades dos alunos assim o requererem. Reiterando a função cooperativa do professor, os Parâmetros Curriculares Nacionais (Brasil, 1998, p. 22) destacam que "Ao professor cabe planejar, implementar e dirigir as atividades didáticas, com o objetivo de desencadear, apoiar e orientar o esforço de ação e reflexão do aluno, procurando garantir aprendizagem efetiva".

Nesse contexto, surge a necessidade de uma ação metodológica alternativa aos modelos tradicionais, que ressignifique, de fato, as práticas de leitura e escrita na escola. É dessa forma que uma ação centrada na implementação de projetos de letramento (Kleiman, 2006) vem a ser 
uma alternativa viável, pois, segundo Kleiman (2007), esses projetos referem-se a um plano de atividades visando ao letramento do aluno e são planejados e operacionalizados por professores que se assumem como agentes de letramento. Tais projetos surgem do interesse real dos alunos, cuja realização envolve uso da escrita em uso (textos que circulam na sociedade), demandando um trabalho coletivo entre alunos e professor, e não uma relação de "[...] papéis sociais estáticos de 'aquele que aprende' e 'aquele que ensina'” (Tinoco, 2010, p. 300). Trata-se, portanto, da realização de uma atividade social não restrita a uma atividade didática, sob pena de criar-se uma situação artificial, contribuindo, assim, para a mobilidade social do sujeito.

Quando o professor opta pelo trabalho com os projetos de letramento nas relações de ensino e aprendizagem, deve atentar, sobretudo, para as necessidades e interesses dos alunos, em especial para o contexto em que estão inseridos. Isso implica uma ação sensível à seleção dos conhecimentos e práticas a serem abordados, de forma que sejam significativos para a vida dos alunos e sua mobilidade social. De acordo com Street (2003), o método etnográfico, que implica, entre outros procedimentos, a observação das situações reais de interação, mostra-se fundamental para a investigação dessas questões e, consequentemente, para um planejamento mais consequente e para a expansão das práticas dos alunos. Nesse viés, não há a necessidade de trabalhar com conteúdos programáticos definidos a priori, pois o ponto de partida para o planejamento dos projetos deve ser a prática social, ou seja, a demanda de situações específicas (Oliveira, 2010a). Segundo Kleiman (2007), o currículo deve deixar de ser visto com algo a ser fielmente seguido e servir como organização dinâmica de conteúdos que vale a pena ensinar, pois o movimento deve ir da prática ao conteúdo (Kleiman, 2006; 2007).

Assim, o projeto de letramento pode ser considerado como uma prática social em que a escrita é utilizada para atingir algum outro fim, que vai além da mera aprendizagem formal da escrita, transformando objetivos circulares como 'escrever para aprender a escrever' e 'ler para aprender a ler' em ler e escrever para compreender e aprender aquilo que for relevante para o desenvolvimento e a realização do projeto (Kleiman, 2009, p. 4).

Como, segundo Kleiman (2009, p. 6), "Adotar o projeto de letramento como modelo didático implica fazer da prática social o elemento estruturante das atividades curriculares", acreditamos ser relevante atentar que tal modelo didático não seja visto como algo pré-concebido e pronto a ser aplicado em qualquer situação e contexto didático, mas sim como um recurso flexível e sensível aos interesses, necessidades e perfis dos alunos, podendo ter seu percurso e atividades modificados em função de demandas e do pleno desenvolvimento do projeto (Kleiman, 2009). É necessário, no entanto, que não se deixem de focalizar os objetivos e metas de tais projetos, sob pena de a atividade não fazer sentido aos alunos.

Educação \& Realidade, Porto Alegre, v. 41, n. 1, p. 259-277, jan./mar. 2016. 
Projetos de Letramento no Ensino Médio

Quanto ao planejamento dos projetos de letramento, Kleiman (2005) e Oliveira (2010a) alertam que o professor deve ser o responsável pela elaboração do método de ensino de suas turmas, portanto deve conhecer o seu aluno, o seu entorno imediato e os variados usos da modalidade escrita da língua para que os métodos sejam sensíveis às particularidades dos participantes. Tais projetos, no entanto, segundo Oliveira (2010a), caracterizam-se por serem realizados coletivamente, exigindo, assim, cooperação, participação e flexibilidade. Isso, para nós, assim como para Oliveira (2010a; 2010b), revela uma aproximação de tais projetos do conceito de comunidade de prática de Wenger (1998). Segundo a autora, na educação, as comunidades de prática equivalem às comunidades de aprendizagem, pois o trabalho empreendido em um projeto de letramento implica o engajamento dos envolvidos, a cooperação, o empreendimento negociado e um repertório compartilhado (Oliveira, 2010a; 2010b), tendo em vista a aprendizagem de seus participantes. Para Oliveira (2010a), a participação e atuação conjunta de professores e alunos em vista de um interesse comum, focalizando, assim, formas de aprender situadas e em estratégias sensíveis aos interesses dos alunos, promove o aluno como ator de sua própria aprendizagem visando à participação nas diversas esferas. Sabemos, contudo, o quão complexas são as relações nesse processo, pois o conflito é constitutivo na interação quando os participantes pertencem a grupos sociais distintos (Kleiman, 1998).

Acreditamos, no entanto, que o que torna um projeto de letramento significativo e bem-sucedido é o zelo a essas questões, especialmente as que se vinculam às caracterizações de uma comunidade de aprendizagem, pois o letramento não é um conjunto de habilidades técnicas uniformes (Street, 2003). Muitos projetos acabam não dando certo, segundo Street (2003), pois apresentam incompatibilidades entre práticas de letramento escolares e familiares dos alunos, revelando uma marginalização das práticas locais e uma imposição de culturas dominantes. Dessa forma, não há um engajamento efetivo dos alunos, razão pela qual Street (2003) sugere a implementação de programas mais sensíveis culturalmente e relacionados ao que realmente as pessoas precisam.

Para Oliveira (2009), os projetos de letramento são melhor contextualizados mediante o trabalho com os gêneros do discurso, isso porque, para participar de determinada prática social, é necessário dominar os gêneros dessa esfera e saber o momento em que usá-los. O trabalho com os gêneros, contudo, não implica a focalização dos aspectos textuais em detrimento das situações de interação e de suas condições de produção, como tem sido visibilizado em muitas situações de ensino (Kleiman, 2006; Street, 2010). Acreditamos, assim como aponta Oliveira (2009), que os gêneros não devem ser vistos como objetos de ensino, o que acaba focalizando sua dimensão textual, mas sim como organizadores da ação de ensinar, implicando uma abordagem significativa e 
situada, ou seja, é necessário ensinar com os gêneros e não sobre os gêneros (Oliveira, 2009).

Essas discussões suscitam a compreensão acerca da necessidade de reorganização de programas de formação docente que visem à representação do professor como agente de letramento (Kleiman, 2006), tendo em vista a autonomia e a mobilização para a participação coletiva e para a criação de projetos de letramento significativos às situações de aprendizagem. Defendemos, assim como Tapias-Oliveira et al. (2010), a necessidade da formação do professor como pesquisador e a construção de saberes por uma perspectiva crítica, implicando uma atitude comprometida desses profissionais com sua construção identitária. Isso contribui, sobretudo, para um diálogo mais efetivo entre universidade e a escola.

\section{Pesquisa-Ação: a elaboração de um projeto de letramento no ensino médio}

Partindo da ancoragem teórica das seções articuladas neste artigo, objetivamos analisar interpretativamente um projeto de letramento implementado pelo PIBID do curso de Letras Português da UFSC, executado em 2010, desenvolvido em uma turma do terceiro ano do Ensino Médio de uma escola pública da rede estadual de ensino, situada em Florianópolis-SC. O PIBID tem como objetivo articular ensino (disciplina optativa reunindo bolsistas), pesquisa (ação escolar por meio da pesquisa-ação) e extensão (ação escolar efetiva). Na ocasião, faziam parte do projeto dez bolsistas, sob a coordenação de uma professora, que eram divididos em grupos com vistas a contemplar as seriações finais do Ensino Fundamental e do Ensino Médio.

Tratava-se de uma pesquisa-ação ${ }^{4}$ (Thiollent, 2008) que contemplou a realização de um projeto de letramento (Kleiman, 2006) dentro do PIBID com vistas a promover a potencialização dos usos da língua materna por parte dos alunos, em interações social e historicamente situadas, nas diferentes esferas da atividade humana, as quais se instituíram por meio dos gêneros do discurso. O projeto se ancorou em uma concepção de língua como objeto social, defendendo o ensino e a aprendizagem da modalidade escrita por meio de usos sociais da língua que se processam nas mais distintas esferas sociais.

Este estudo focaliza, em especial, um dos projetos de letramento empreendidos pelo PIBID, o qual tinha como participantes de pesquisa 21 alunos do terceiro ano do Ensino Médio, com faixa etária média de dezoito anos, representativos de uma classe socioeconomicamente desprivilegiada. O objetivo era implementar o projeto de letramento por meio de alguns gêneros do discurso, os quais não foram definidos previamente em função da própria natureza dos projetos de letramento: ser elaborados conforme as demandas do contexto educacional (Kleiman, 2006). Dessa forma, os procedimentos metodológicos se deram a partir 
Projetos de Letramento no Ensino Médio

do estudo do projeto político pedagógico da escola, da observação de um conjunto de aulas de Língua Portuguesa na série em que se deu a pesquisa-ação e de um instrumento de geração de dados (questionário) no que respeitava à constituição familiar, entorno sociocultural e econômico, vivências com leitura e itens afins, visando traçar um diagnóstico inicial para o delineamento do perfil da turma e do trabalho ali desenvolvido, de forma a se proceder a uma abordagem situada (Barton; Hamilton; Ivanic, 2000).

No que toca aos dados do questionário quanto às atividades de leitura e escrita no contexto extraescolar, considerando a importância das demandas não somente escolares dos alunos, evidenciou-se a predominância de acesso a textos que circulam nas redes sociais, muitos deles relacionados a assuntos sobre o vestibular, ENEM, família e notícias de fatos atuais. Observou-se, também, uma predileção por textos curtos, com linguagem mais informal e, preferencialmente, temáticas com humor. Além disso, quanto à esfera do lar, dezessete alunos informaram residir com os pais, enquanto o restante mencionou morar com tios, irmãos e com o cônjuge. Em se tratando da formação escolar desses familiares, boa parte cursou até o Ensino Fundamental, havendo a indicação de apenas três com Ensino Superior completo.

Nesse sentido, tendo em vista o diagnóstico inicial da turma, bem como o interesse em prestar vestibular pela ampla maioria dos alunos ${ }^{5}$ e as sugestões da professora titular da turma, que, em princípio, teria um cronograma a cumprir, optou-se pelo trabalho com o gênero crônica articulado com o gênero notícia, focalizando as ações com a produção textual escrita. Como os alunos estavam lendo um livro de crônicas selecionado para o vestibular, pensou-se em trazer mais crônicas, dando, assim, continuidade ao que estavam estudando. Tal escolha parte da compreensão de que o trabalho com gêneros articulados torna o processo de ensino e aprendizagem mais próximo das situações reais de uso desses gêneros, considerando que grande parte deles tem entre si uma relação bastante estreita, como é o caso da crônica e da notícia, por exemplo. Somado a isso, o fato de que uma mesma temática pode nortear a construção de uma variedade de gêneros contribui para uma expansão do conhecimento no que toca ao uso e finalidades de uma gama maior de gêneros do discurso.

Como podemos depreender até aqui, o planejamento dos procedimentos em questão insere-se numa perspectiva de elaboração de um projeto de letramento, pois parte de um interesse coletivo e visa à ampliação e expansão do conhecimento e das práticas sociais, afastando-se das práticas comumente implementadas no modelo autônomo de letramento. Além disso, durante a elaboração do projeto, sentiu-se a necessidade de atuar como agentes de letramento, articulando e mobilizando recursos e estratégias em direção à modificação da realidade.

O desenvolvimento do projeto de letramento na turma do terceiro ano do Ensino Médio se constituiu de duas aulas semanais ao longo de 
um bimestre e tinha como foco a leitura de crônicas, o estudo de textos de referência sobre a estrutura composicional e finalidades da crônica para discussões em classe sobre o tema e a articulação com o gênero notícia, dada a interface da crônica entre literatura e jornalismo e dado o diálogo com acontecimentos do cotidiano. O foco visava o contato com o gênero nas interações sociais e a compreensão leitora dos textos nele materializados, almejando a produção de uma crônica, o que implicava a busca pela autoria no gênero, visando ao estabelecimento de relações intersubjetivas. Procurou-se, ainda, focalizar crônicas e notícias e discutir as implicações morfológicas na construção desses gêneros através da leitura, produção de textos (orais e escritos), análise e reflexão sobre os usos da linguagem. Finalizada essa etapa, foi sugerida aos alunos a organização de um blog para a veiculação das crônicas produzidas.

A expectativa era a de que os alunos reconhecessem a crônica como gênero do discurso, identificando especificidades que a instituem como tal, chamando atenção para a esfera de circulação (esfera do jornalismo, esfera da literatura, esfera da internet, esfera acadêmica, esfera escolar, esfera da recreação etc.), identificando os suportes (jornal, livro, blogs, revistas) e fazendo uma discussão sobre as condições de produção do gênero crônica. Por meio desses procedimentos, desejou-se ampliar a mobilidade do aluno na esfera em que a crônica circula e não propriamente na aprendizagem da constituição formal do gênero. Percebeu-se, contudo, que, em alguns momentos, os alunos não se mostravam interessados em realizar a atividade ou participar das aulas e sentiam um pouco de dificuldade na discussão da temática das crônicas, o que tornou o processo um pouco difícil. Nesse sentido, durante as etapas do projeto, houve necessidade de mudança de temática em função dos interesses dos alunos e da demanda da situação comunicativa (Kleiman, 2006; 2007; 2009), caracterizando, mais uma vez, o trabalho metodológico com os projetos de letramento. Partindo do princípio que para que seja escrita uma crônica o escritor deva dominar minimamente $o$ assunto, promoveu-se uma discussão sobre a temática escolhida, o que envolvia os textos do gênero notícia, focalizando, assim, a alimentação temática para a produção textual.

Apesar de se constatar um possível engajamento (ao menos tímido) dos alunos, a solicitação de uma produção textual gerou protestos. Os alunos não consideravam útil ou necessário escrever, mesmo sabendo que essas produções seriam publicadas em um blog que seria lido, comentado e referenciado por outros. A hipótese em torno dessa situação é a de que os alunos não compreenderam que as leituras e as discussões das primeiras aulas estavam diretamente relacionadas à produção de uma crônica e que produzir um texto é posicionar-se, é ter o que dizer, ter a quem dizer, ter como dizer e ter razões para dizer (Geraldi, 2003). Tentou-se suprir o que dizer e o a quem dizer, mas não foi possível incidir sobre os motivos e sobre as estratégias do dizer, e isso teve como efeito a enorme dificuldade de escrita e da enunciação desses alunos/sujeitos. 
Não houve, nesse sentido, engajamento e repertório compartilhado na interação proposta.

Tais reações dos alunos parecem estar associadas, em boa medida, à concepção das produções de texto como meros artefatos escolarizados (Geraldi, 2003; Antunes, 2003), os quais apresentam o único propósito de serem avaliados e corrigidos pelos docentes, sem fins interlocutivos reais. Além disso, os alunos demonstraram ter pouca segurança em enunciar o seu dizer a interlocutores, em sua grande parte, mais experientes (docentes e alunos da graduação), convergindo com discussões de Pfeiffer (1995) quanto às valorações enraizadas em torno da atividade de escrita de que só é autor aquele que tem autoridade, quando não o dom da inspiração. Assim, tais estudantes, em geral, tendem a não se ver como autores de textos, pois se sentem obrigados a desenvolver uma atividade distante da posição que ocupam, ou seja, "[...] veem-se [numa] posição 'subalterna' de tentar convencer seu professor ou outros possíveis leitores de que seu texto é "bom" (Pfeiffer, 1995, p. 53). Desse modo, o projeto de dizer (Bakhtin, 2011) desses sujeitos, embora se tenha observado o esforço dos bolsistas em antecipar as condições de produção e a situação comunicativa dos textos, não foi efetivado, pois não partiu de um querer dizer (Antunes, 2003) desses sujeitos, sendo, também, associado à simples exigência de realização de tarefas escolares com fim em si mesmas.

A produção da crônica por parte dos alunos demonstrou uma grande dificuldade de agenciamento de conteúdo temático, linguístico e especialmente das finalidades e caracterizações do gênero crônica nos processos de referenciação, seleção lexical adequada ao contexto e ao interlocutor e no agenciamento de conhecimentos de mundo. Muitas das supostas crônicas se afastavam bastante das finalidades, da construção composicional, do estilo e das condições de produção de uma crônica, tomada em sua relativa estabilidade (Bakhtin, 2003). Inferimos que tais dificuldades e a falta de engajamento em propostas mediadas pela escrita nos remetem à compreensão de que os eventos de letramento (Heath, 2001) trabalhados na escola, em boa medida, não ganharam sustentação nas práticas de letramento (Street, 1988) dos alunos, não significando, dessa forma, para eles.

Apesar do esforço em hibridizar as práticas de letramentos escolares (dominantes) e familiares (vernaculares), dispôs-se de pouco tempo, somado a imprevistos de ordem burocrática da escola, para conscientizar os alunos da importância das práticas empreendidas pelo projeto e instigá-los, assim, a uma atitude de cooperação e engajamento em torno de um interesse comum, característicos de uma comunidade de aprendizagem (Oliveira, 2010a; 2010b). Tais acontecimentos repercutiram negativamente na proposta final, a reescrita dos textos a partir das sugestões apontadas pelos bolsistas, tendo em vista a veiculação em um blog criado para a circulação dessas crônicas. Muitos dos alunos 
revelaram não ter interesse na publicação, pois temiam a reação do público-alvo (alunos da UFSC, professores e eventuais leitores). Além disso, devido ao término do bimestre e, consequentemente, das atividades do PIBID na escola, as refacções que deveriam ter sido encaminhadas por $e$-mail para a publicação no suporte blog não foram entregues pelos alunos.

Tais aspectos acabaram evidenciando que a forma como as atividades e as relações interpessoais em sala de aula foram encaminhadas, somada a um curto espaço de tempo, não conquistaram a adesão dos alunos, tornando visível uma não concretização do projeto de fato, revelando um distanciamento desse projeto e da situação de interação em sala de aula de uma comunidade de aprendizagem (Oliveira, 2010a; 2010b) marcada pelo engajamento dos envolvidos no processo, pela cooperação, pelo empreendimento negociado e repertório compartilhado. Isso vem a deixar explícita a complexidade de planejamento e elaboração de um projeto de letramento, demandando ressignificações metodológicas e um trabalho mais acurado no que toca aos processos de hibridização dos letramentos locais e globais (Street, 2003), de forma a ressignificar e ampliar as práticas de letramentos dos alunos.

\section{Considerações Finais}

Diante da discussão aqui desenvolvida, observou-se que, embora houvesse uma tentativa de ressignificação das práticas escolares, por meio da implementação de projetos de letramento, os quais consideram os interesses coletivos e as demandas dos sujeitos, não houve engajamento por parte dos alunos. Tal resultado evidencia uma não convergência das práticas de letramento escolar (dominantes) e familiares (vernaculares), tal como demonstrou Street (2003) em suas pesquisas de caráter etnográfico em vilarejos, bem como a associação de práticas de produção de texto a atividades meramente escolares e artificiais (Geraldi, 2003; Antunes, 2003).

Fica claro, assim, que a reformulação das práticas de ensino e aprendizagem deve se dar a partir de uma atitude do professor como agente de letramento por meio de um trabalho mediado pelos projetos de letramento sensíveis culturalmente e situados, pois tais posturas contribuem para tornar as práticas educativas mais significativas e menos artificiais possíveis ${ }^{6}$ das práticas cotidianas. Essa nova postura, no entanto, não garante um trabalho metodológico bem-sucedido, pois o que determina o sucesso e o alcance dos objetivos traçados é a aproximação das situações de interação em sala de aula (e consequentemente dos projetos de letramento) a uma comunidade de aprendizagem (Oliveira, 2010a; 2010b), sobretudo o engajamento dos envolvidos no processo. Desse modo, a experiência vivenciada pelos bolsistas do PIBID, embora não tenha atingido os resultados esperados, mostrou-se válida para suas formações como docentes, tendo em vista a necessidade de ressig- 
nificações constantes das ações metodológicas e de um olhar crítico às próprias atuações.

Defendemos, portanto, que a superação desse quadro possa iniciar-se a partir da reformulação de cursos de formação (inicial ou continuada), visando à habilitação reflexiva dos professores e uma atitude autônoma em relação à atuação em novos contextos (Kleiman, 2006). Isso implica, entre outras ações, a necessidade de uma elaboração didática (Halté, 2008) que contemple, de fato, as vivências dos alunos e incida sobre elas, de modo a facultar aos alunos uma maior mobilidade nas mais distintas situações de interação. Por conta disso, estudos mais aprofundados sobre a implementação de projetos de letramento, que oportunizem o contato também com as vivências extraescolares, fazem-se necessários à ressignificação constante das ações metodológicas com a escrita.

Recebido em 20 de fevereiro de 2015 Aprovado em 21 de outubro de 2015

\section{Notas}

1 Corrente teórica surgida na década de 1980 que estuda a escrita em seus usos sociais, de forma situada, sob perspectivas etnográficas. Entre seus teóricos estão nomes como Street, Hamilton, Barton, Heath e Ivanic.

2 Os estudos de base etnográfica têm contribuído de forma significativa para o campo da Linguística Aplicada, pois permite ao investigador o contato direto com o campo estudado e um olhar aprofundado sobre uma situação que se dá em seu contexto dinâmico e natural (André, 2008), implicando o trabalho com sujeitos reais e historicamente situados, sem haver nesse contexto o controle do ambiente investigado.

3 Assim como Street (2003), não acreditamos numa polarização extrema dos modelos autônomo e ideológico de letramento, pois há um imbricamento natural entre eles. Enquanto o modelo autônomo está imerso em uma ideologia, aparentemente neutralizada, o modelo ideológico reconhece as habilidades técnicas envolvidas na aquisição da escrita.

4 “[...] a pesquisa-ação é um tipo de pesquisa social com base empírica que é concebida e realizada em estreita associação com uma ação ou com a resolução de um problema coletivo e no qual os pesquisadores e participantes representativos da situação ou do problema estão envolvidos de modo cooperativo ou participativo" (Thiollent, 2008, p. 16).

5 Apenas um aluno, do grupo dos 21, informou que não tinha interesse em prestar vestibular e dar prosseguimento aos estudos.

6 Reconhece-se a artificialidade constitutiva (Halté, 2008) do trabalho com os gêneros no processo de escolarização, mas isso não implica necessariamente uma prática sem sentido, e sim numa adaptação das situações reais de interação dos gêneros às práticas escolares, determinando, assim, objetivos específicos. 


\section{Referências}

ANDRÉ, Marli Eliza Dalmazo Afonso de. Estudo de Caso em Pesquisa e Avaliação Educacional. 3 ed. Brasília: Liber Livro Editora, 2008.

ANTUNES, Irandé. Aula de Português - encontro \& interação. São Paulo: Parábola Editorial, 2003.

BAKHTIN, Mikhail Mikhailovich. Estética da Criação Verbal. São Paulo: Martins Fontes, 2003.

BARTON, David; HAMILTON, Mary. La literacidad entendida como práctica social. In: ZAVALA, Virginia; NIÑO-MURCIA, Mercedes; AMES, Patrícia (Org.). Escritura y Sociedad: nuevas perpectivas teóricas y etnográficas. Lima: RED, 2004. P. 109-139

BARTON, David; HAMILTON, Mary; IVANIC, Roz. Situated Literacies. London: Routledge, 2000.

BRASIL. Secretaria de Educação Fundamental. Parâmetros Curriculares Nacionais: terceiro e quarto ciclos do ensino fundamental: língua portuguesa. Brasília: MEC/SEF, 1998.

BRITTO, Luiz Percival Leme. A Sombra do Caos: ensino de língua x tradição gramatical. São Paulo: Mercado de Letras, 1997.

DUARTE, Newton. Vigotski e o ‘Aprender a Aprender’: crítica às apropriações neoliberais e pós-modernas da teoria vigotskiana. 2. ed. Campinas: Editora Autores Associados, 2001.

FREIRE, Paulo. A Importância do Ato de Ler: em três artigos que se completam. 47. ed. São Paulo: Cortez, 2006.

FREIRE, Paulo. Pedagogia do Oprimido. Rio de Janeiro: Paz e Terra, 1975.

GEE, James Paul. Background to the 'New Literacy Studies'. In: GEE, James Paul. Social Linguistics and Literacies. The Falmer Press, 1994. P. 48-70.

GERALDI, João Wanderley. Portos de Passagem. 4. ed. São Paulo: Martins Fontes, 2003. HALTÉ, Jean-François. O espaço didático e a transposição. Tradução de Ana Paula Guedes e Zélia Anita Viviani. Fórum Linguístico, Florianópolis, v. 5, n. 2, p. 117-139, jul./dez. 2008.

HAMILTON, Mary. Expanding the new literacy studies: using photographs to explore literacy as social practice. In: BARTON, David; HAMILTON, Mary; IVANIC, Roz (Org.). Situated Literacies. London: Routledge, 2000. P. 16-34.

HEATH, Shirley Brice. What no Bedtime Story Means: narrative skills at home and school. In: DURANTI, Alessandro (Org.). Linguistic Anthropology: a reader. Oxford: Blackwel, 2001. P. 318-342.

KALANTZIS, Mary; COPE, Bill. Multiliteracies. London and New York: Routledge, 2006.

KALMAN, Judith. El acesso a la cultura escrita: la participación social y la apropriación de conocimientos en eventos cotidianos de lectura y escritura. Revista Mexicana de Investigación Educativa, v. VIII, n. 17, p. 37-66, jan./abr. 2003.

KLEIMAN, Angela (Org.). Os Significados do Letramento: uma nova perspectiva sobre a prática social da escrita. Campinas: Mercado de Letras, 1995.

KLEIMAN, Angela. A Construção de Identidades em Sala de Aula: um enfoque interacional. In: SIGNORINI, Inês. Linguagem e Identidade. Campinas: Mercado das Letras, 1998. P. 267-302.

KLEIMAN, Angela. Preciso "Ensinar" o Letramento? Não basta ensinar a ler e escrever? Campinas: Cefiel - Unicamp; MEC, 2005.

Educação \& Realidade, Porto Alegre, v. 41, n. 1, p. 259-277, jan./mar. 2016. 
KLEIMAN, Angela. Processos Identitários na formação profissional: o professor como agente de letramento. In: CORRÊA, Manoel Luiz Gonçalves; BOCH, Françoise (Org.). Ensino de Língua: representação e letramento. Campinas: Mercado das letras, 2006. P. 75-91.

KLEIMAN, Angela. Letramento e suas Implicações para o Ensino de Língua Materna. Signo, Santa Cruz do Sul, v. 32, n. 53, p. 1-25, dez. 2007.

KLEIMAN, Angela. Projetos de letramento na educação infantil. Revista Caminhos em Linguística Aplicada, UNITAU, v. 1, n. 1, 2009, p. 1-10. Disponível em: <http://www.unitau.br/caminhosla>. Acesso em: 01 fev. 2015.

MOITA-LOPES, Luiz Paulo (Org.). Por uma Linguística Aplicada Indisciplinar. São Paulo: Parábola, 2006.

OLIVEIRA, Maria do Socorro. Gêneros Textuais e Letramento. In: SIMPÓSIO INTERNACIONAL DE ESTUDOS DE GÊNEROS TEXTUAIS, 5, 2009, Caxias do Sul. Anais... Caxias do Sul: Educs, 2009. P. 1-20.

OLIVEIRA, Maria do Socorro. Variação Cultural e Ensino/Aprendizagem de Língua Materna: os projetos de letramento em comunidades de aprendizagem. In: VÓVIO, Claudia; SITO, Luanda; DE GRANDE, Paula (Org.). Letramentos: rupturas, deslocamentos e repercussões de pesquisa em linguística aplicada. Campinas: Mercado de letras, 2010a. P. 121-140.

OLIVEIRA, Maria do Socorro. O Papel do Professor no Espaço da Cultura Letrada: do mediador ao agente de letramento. In: SERRANI, Silvana (Org.). Letramento, Discurso e Trabalho Docente. Vinhedo: Editora Horizonte, 2010b. P. 40-55.

PFEIFFER, Claudia R. C. Que Autor é Este? 1995. Dissertação (Mestrado em Linguística) - Instituto de Estudos da Linguagem, Universidades Estadual de Campinas, Campinas, 1995.

ROJO, Roxane. Letramentos Múltiplos, Escola e Inclusão Social. São Paulo: Parábola Editorial, 2009.

SOARES, Magda. Letramento: um tema em três gêneros. Belo Horizonte: Autêntica, 1998.

STREET, Brian. Literacy in Theory and Practice. Cambridge: CUP, 1984.

STREET, Brian. Practices and Literacy Myths. In: SALJO, Roger (Ed.). The Written World: studies in literate thought and action. Berlim/Nova Iorque: Springer-Verlag, 1988. P. 59-72.

STREET, Brian. Abordagens Alternativas ao Letramento e Desenvolvimento. Teleconferência Unesco Brasil Sobre 'Letramento e Diversidade’, out. 2003.

STREET, Brian. Os Novos Estudos sobre o Letramento: histórico e perspectivas. In: MARINHO, Marildes; CARVALHO, Gilcinei Teodoro (Org.). Cultura Escrita e Letramento. Belo Horizonte: Editora UFMG, 2010. P. 33-53.

TAPIAS-OLIVEIRA, Eveline Mattos et al. Da Construção Autoral à Formação do Professor: percursos, mudanças e novos horizontes In: VÓVIO, Claudia; SITO, Luanda; DE GRANDE, Paula (Org.). Letramentos: rupturas, deslocamentos e repercussões de pesquisa em linguística aplicada. Campinas: Mercado de letras, 2010. P. 201-202.

THIOLLENT, Michel. Metodologia da Pesquisa-Ação. 16. ed. São Paulo: Cortez, 2008. 
TINOCO, Glícia Azevedo. Pluralidade Cultural, Projeto de Letramento, FormAÇÃO Docente: ressignificações possíveis. In: VÓVIO, Claudia; SITO, Luanda; DE GRANDE, Paula (Org.). Letramentos: rupturas, deslocamentos e repercussões de pesquisa em linguística aplicada. Campinas: Mercado de letras, 2010. P. 296-314.

VIGOTSKI, Lev Semenovich. A Formação Social da Mente. São Paulo: Martins Fontes, 2000 [1978].

WENGER, Etienne. Communities of Practice: learning, meaning, and identity. New York: Cambridge University Press, 1998.

Karoliny Correia é graduada em Letras - Língua Portuguesa e Literaturas de Língua Portuguesa e mestra em Linguística pela Universidade Federal de Santa Catarina (UFSC). Atualmente é doutoranda do Programa de Pós-graduação em Linguística da UFSC e professora efetiva de Língua Portuguesa no Instituto Federal de Educação, Ciência e Tecnologia de Santa Catarina (IF-SC).

E-mail:karol.correiaa@gmail.com 